\title{
DIFFERENTIAL SUSCEPTIBILITY OF RAT EMBRYOS TO METHYL METHANESULFONATE DURING THE PREGASTRULATION PERIOD
}

\author{
Ryohei YOKOI ${ }^{1,2}$, Satoshi SUDA ${ }^{2}$, Kazuo KOBAYASHI ${ }^{2}$, Junji KURODA², \\ Hiroshi KUSAMA ${ }^{2}$, Hiroshi KAGAMI ${ }^{3}$ and Tamao $\mathrm{ONO}^{3}$ \\ ${ }^{1}$ Interdisciplinary Graduate School of Science and Technology, Shinshu University, \\ 8304 Minamiminowa, Kamiina, Nagano 399-4598, Japan \\ ${ }^{2}$ Toxicology Research Laboratories, Kissei Pharmaceutical Co., Ltd., \\ 2320-1 Maki, Hotaka, Minamiazumi, Nagano 399-8305, Japan \\ ${ }^{3}$ Faculty of Agriculture, Shinshu University, \\ 8304 Minamiminowa, Kamiina, Nagano 399-4598, Japan
}

(Received August 1, 2007; Accepted September 7, 2007)

\begin{abstract}
The effects of exposure of pregnant rats to methyl methanesulfonate (MMS), an alkylating agent, during the pregastrulation period on embryonic and placental development were investigated. SD rats were treated orally with a single dose of MMS $(200 \mathrm{mg} / \mathrm{kg})$ in the morning of gestation days 0 , $1,2,3,4,5$, or 6 (GD0 to GD6 groups, respectively). The uterine contents including fetuses and placentas of the dams were examined on gestation day 20. The individual fetuses and placentas were weighed, and the fetuses were examined for external, visceral and skeletal anomalies. The progress of ossification was also evaluated. Both pre- and postimplantation embryonic mortalities were higher in the GD0 group than in the control group. The postimplantation loss was also increased for the GD3, GD4 and GD6 groups. Fetal malformations were rare in survivors of all the MMS-treated groups. Intrauterine growth retardation was apparent for fetuses in groups GD5 and GD6. In addition, placental weight was reduced in the GD6 group, but it was increased in the GD0 group. Effects of MMS on embryonic mortality or on fetal or placental growth were absent or minimal in the GD1 and GD2 groups. These results suggest that the susceptibility of rat embryos to MMS varies during the pregastrulation period.
\end{abstract}

KEY WORDS: Methyl methanesulfonate, Rat, Pregastrulation, Postimplantation loss, Intrauterine growth retardation

\section{INTRODUCTION}

The pregastrulation mammalian embryo had been thought to exhibit an all-or-none response to chemical or physical agents: the embryo either died during gestation or it survived free of malformations (Russell and Russell, 1950, 1952; Russell, 1950, 1954). It was subsequently found, however, that exposure of pregastrulation mouse embryos to various agents, including $\mathrm{x}$ radiation, mutagens, or retinoic acid, can result in developmental malformations (Nagao et al., 1986, 1991, 1997, 2000; Generoso et al., 1987, 1988, 1991; Rutledge et al., 1992; Nagao, 1994, 1996; Jacquet et al., 1995). Indeed, the zygote and two-cell embryo in mice represent a window of susceptibility to the experimental induction of congenital anomalies by certain mutagens (Rutledge et al., 1992; Rutledge, 1997). A single intraperitoneal injection of pregnant mice with methyl methanesulfonate (MMS), an alkylating agent, at the pregastrulation stage increases pre- and postimplantation embryonic mortality and induces intrauterine growth retardation as well as malformations in term fetuses (Generoso et al., 1991; Rutledge et al., 1992; Rutledge, 1997). Given that few studies have examined developmental toxicology except in mice, with treatment of dams at pregastrulation stages of embryonic development, we have now investigated the effects of MMS on developing embryos, including the placenta,

Correspondence: Ryohei YOKOI (E-mail: ryohei_yokoi@pharm.kissei.co.jp) 
after oral treatment of pregnant rats at various times during the pregastrulation period. The rat is the most commonly used experimental animal for toxicity evaluation and has a longer pregastrulation period compared with that in the mouse. The preimplantation period is approximately 4 days in mice and 5 days in rats (Witschi, 1962; Iannaccone et al., 1987).

\section{MATERIALS AND METHODS}

\section{Animals}

All animal experiments were performed in accordance with the Guide to the Care and Use of Experimental Animals of the Toxicology Research Laboratories, Kissei Pharmaceutical Co. Ltd. Specific pathogen-free Crj:CD(SD)IGS (SD) rats were obtained from Charles River Japan (Shiga, Japan). The animals were maintained in a barrier facility at a temperature of $23 \pm$ $2^{\circ} \mathrm{C}$, relative humidity of $55 \pm 15 \%$, and 12-hr-light, 12-hr-dark cycle (light on from 0800 to $2000 \mathrm{hr}$ ). The animals were housed individually in stainless steel mesh cages ( 260 by 230 by $180 \mathrm{~mm}$ ) and were allowed free access to tap water and a pellet diet (CE-2; CLEA Japan, Tokyo, Japan) throughout the quarantine, acclimation, and study periods. After the quarantine and acclimation periods, females with a vaginal impedance of $>3.0 \mathrm{k} \Omega$ (Vaginal Impedance Checker, MuromachiKikai, Tokyo) were selected for mating.

\section{Chemicals}

MMS (99.9\%; Aldrich, Milwaukee, WI, USA) was dissolved in distilled water (JP grade; Otsuka Pharmaceutical Industries, Tokushima, Japan). The MMS solution was prepared freshly on each treatment day.

\section{Mating and Treatment}

One male rat and one female rat were cohoused in the male's cage overnight. Successful copulation was defined by the presence of a vaginal plug or of sperm in the vaginal smear on the morning after mating, with this day being designated as gestation day 0 . Female rats that had copulated successfully were assigned randomly to experimental groups. Each group of dams was treated orally with a single dose of MMS (200 mg per kg of body mass) in the morning of gestation days $0,1,2,3,4,5$, or 6 , with the corresponding experimental groups being designated GD0 to GD6, respectively. These times of MMS administration represent developmental stages were the zygote (GD0), two-cell (GD1), two- to four-cell (GD2), eight-cell/ morula (GD3), blastocyst (GD4), hatched blastocyst/ initiation of implantation (GD5) and implantation (GD6), respectively (Witschi, 1962; Yasuda and Sato, 1980; Aliverti et al., 1982; Graeter et al., 1998). The dose $(200 \mathrm{mg} / \mathrm{kg})$ was chosen based on the oral LD50 for rats $(225 \mathrm{mg} / \mathrm{kg}$, Material Safety Data Sheet, http:// physchem.ox.ac.uk/MSDS/ME/ methyl_methanesulfonate.html).

The control group consisted of untreated dams. The drug was administered orally because it was a general route in the evaluation of developmental toxicity.

\section{Cesarean section}

Sixty-eight females (7-9 pregnant animals in each group) were euthanized by carbon dioxide inhalation in the afternoon of gestation day 20 . The intrathoracic and intraperitoneal organs were observed macroscopically, the ovaries and uterus were removed, and the numbers of corpora lutea and implantations were counted for each side separately. Each implantation was numbered starting from the right uterine horn. The intrauterine distribution of fetuses, the number of live fetuses or the number and type of dead embryos or fetuses (implantation sites, placental remnants, resorbed embryos, or macerated fetuses), and any amniotic or placental abnormalities were observed and recorded. For hematologic examination dams were anesthetized with diethylether while blood sampling and then they were euthanized by exsanguination in the afternoon of gestation day 20. Blood samples were collected from the abdominal aorta of three to five dams in the GD0, GD6, and control groups and the examination was performed with the use of a Technicon $\mathrm{H} \cdot 1 \mathrm{E}$ system (Bayer-Medical, Tokyo).

\section{Fetuses}

All surviving fetuses on gestation day 20 were examined for external anomalies (including the oral cavity) and the sex was identified. The fetuses and placentas were weighed individually. The fetuses were then euthanized by intraperitoneal administration of thiopental sodium (Ravonal; Tanabe Seiyaku, Osaka, Japan). The fetuses and placentas were fixed in $10 \%$ phosphate-buffered formaldehyde solution. The fetal intraperitoneal visceral organs were examined macroscopically, and the intrathoracic visceral organs were examined after microdissection (Nishimura, 1974). Skeletal examination was performed on fetuses stained with alizarin red S (Jensh and Brent, 1966); the specimens were evaluated with a stereoscopic microscope for skeletal anomalies and variations as well as for 
Susceptibility of rat embryos to methyl methanesulfonate.

retardation of ossification. The numbers of ossified metacarpal and metatarsal bones, sacral and caudal vertebral bones, and sternebrae were also counted to estimate the progress of ossification.

\section{Statistical analysis}

Data are presented as means \pm S.D. unless indicated otherwise. The Mann-Whitney rank sum test (Ichihara, 1996) with the Yates correction for ties was used to compare the number of corpora lutea, the number of implantations, the number of live fetuses, fetal weight, placental weight, hematologic parameters, indices of progression of ossification, preimplantation loss, postimplantation loss, or the frequency of fetuses showing malformations or variations. The chi-square test (Fisher, 1922) was used to analyze the pregnancy rate. A p value of $<0.05$ was considered statistically significant.

\section{RESULTS}

\section{Fertility and cesarean section}

Uterine content of MMS-treated rats was examined by cesarean section on gestation day 20 (Table 1). There was no significant difference in the pregnancy rate or in the numbers of corpora lutea or implantations between the various MMS-treated groups (GD0 to GD6) and the control group. However, the number of live fetuses in the GD0, GD3, GD4, or GD5 groups was significantly lower than that in the control group. Pooling of the implantation data for the GD3 to GD6 groups also revealed a significant difference with the control group. A significant increase in preimplantation loss was apparent for group GD0, whereas postimplantation loss was significantly increased in groups GD0, GD3, GD4, and GD6, as compared with the control group. Pooling of the fetal mortality data for groups GD3 to GD6 also revealed a significant increase compared with the control group. Fetal weight was significantly decreased for both sexes in the GD5 and GD6 groups compared with that in the control group. In addition to the retardation in intrauterine growth apparent in the GD6 group, this group exhibited a significant decrease in placental weight. In contrast, placental weight was significantly increased in the GD0 group. No significant differences in erythrocyte parameters of dams on gestation day 20 were detected between the GD0 or GD6 groups and the control group (Table 2).

\section{Fetal examinations}

The results of fetal examination for external malformations as well as for visceral and skeletal abnormalities are shown in Tables 3 to 5, respectively. One fetus in the GD4 group and four fetuses in the GD6 group showed external malformations. The incidence of visceral or skeletal malformations or variations was similar in the experimental groups (GD0 to GD6) and the control group, with the exception that the incidence of fetuses with variations was significantly decreased for the GD5 and GD6 groups (Table 4). Evaluation of the progress of ossification revealed that the number of sacral-caudal vertebral bones was significantly decreased in group GD5 (Table 6). The other indices of ossification progression (the numbers of ossified metacarpal and metatarsal bones and sternebrae) were similar among all groups.

\section{DISCUSSION}

We have shown that treatment of pregnant rats with MMS on gestation days $0,3,4$, or 6 resulted in a significant increase in postimplantation loss, whereas such treatment on gestation days 1,2 , or 5 did not significantly increase embryonic mortality. Although a significant increase in postimplantation mortality was not apparent in the GD5 group, the pooled data for groups GD3 to GD6 showed a significant increase compared with the control group. A significant increase in preimplantation loss was observed only in the GD0 group. Treatment of mouse embryos with MMS at preimplantation stages was previously shown to induce their death both in vitro (Fabro et al., 1984; Iannaccone et al., 1987) and in vivo (Generoso et al., 1991; Rutledge et al., 1992; Nagao et al., 1997; Rutledge, 1997). Treatment of male rats or mice with MMS induces a dominant lethal phenotype in embryos derived from the exposed sperm (Ehling and Neuhauser-Klaus, 1990; Ashby et al., 1996) and chromosomal damage in gametes results in such a phenotype of embryos (Brewen et al., 1975; Katoh and Tanaka, 1980). Treatment of pregnant female mice with MMS at the zygote stage, however, induces fertilized eggs with degenerated chromosomes not to have aberrations at the first cleavage stage (Tanaka, 1981).

The lack of both pre- and postimplantation losses in the GD1 and GD2 groups in the present study may be related to the fact that embryos at the two- to fourcell stages are moving through the oviduct to the uterus and so may be exposed to lower concentrations of MMS than are those at other stages. Alternatively, 
R. YOKOI et al.

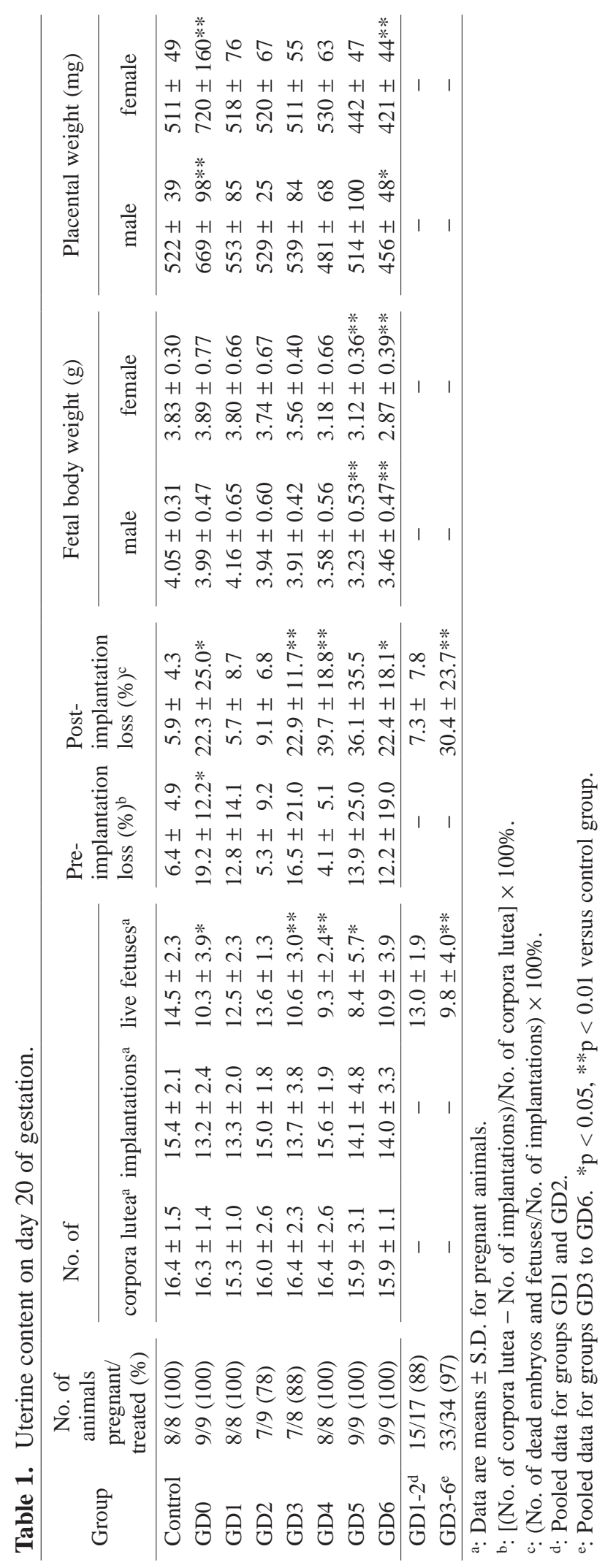


Susceptibility of rat embryos to methyl methanesulfonate.

embryos on gestation days 0 and 3 to 6 may be more sensitive to MMS than are those on days 1 and 2 .

A single intraperitoneal injection with MMS into female mice on day 0 of gestation, corresponding to the zygote stage of embryonic development, was previously shown to result in congenital anomalies (Generoso et al., 1991). The incidence increased approximately 7- and 12-fold at the dose of 75 and 100 $\mathrm{mg} / \mathrm{kg}$, respectively. Nagao et al. (1997) showed that intraperitoneal injection of mouse dams with MMS at a dose of $80 \mathrm{mg} / \mathrm{kg}$ on gestation day 3 (blastocyst stage) induced various types of external and skeletal malformations in the fetuses. In contrast, we have now shown that, whereas gavage administration of MMS at the pregastrulation stage induced embryonic mortality and fetal growth retardation in rats, it did not result in a high incidence of fetal malformations. It was also reported that treatment of mouse embryos at the 16-

Table 2. Erythrocyte parameters of dams on gestation day 20.

\begin{tabular}{lcccccc}
\hline Group & RBC $\left(10^{6} / \mu \mathrm{l}\right)$ & HGB $(\mathrm{g} / \mathrm{dl})$ & HCT $(\%)$ & MCV $(\mathrm{fl})$ & $\mathrm{MCH}(\mathrm{pg})$ & $\mathrm{MCHC}(\mathrm{g} / \mathrm{dl})$ \\
\hline Control & $5.9 \pm 0.2$ & $12.3 \pm 0.3$ & $35.5 \pm 0.6$ & $60.1 \pm 2.4$ & $20.8 \pm 0.8$ & $34.6 \pm 0.7$ \\
GD0 & $6.0 \pm 0.6$ & $12.0 \pm 1.0$ & $35.4 \pm 3.3$ & $58.7 \pm 1.2$ & $20.0 \pm 0.7$ & $34.1 \pm 0.6$ \\
GD6 & $6.1 \pm 0.4$ & $12.0 \pm 0.6$ & $36.6 \pm 3.0$ & $60.0 \pm 4.3$ & $19.7 \pm 1.0$ & $32.9 \pm 1.1$ \\
\hline
\end{tabular}

RBC: red blood cells, HGB: hemoglobin, HCT: hematocrit, MCV: mean corpuscular volume,

$\mathrm{MCH}$ : mean corpuscular hemoglobin, MCHC: mean corpuscular hemoglobin concentration.

Data are means \pm S.D. from three to five animals.

Table 3. Frequency of external malformations in live fetuses.

\begin{tabular}{lcc}
\hline Group & $\begin{array}{c}\text { No. of litters with } \\
\text { malformation / total }\end{array}$ & $\begin{array}{c}\text { No. of fetuses with } \\
\text { malformation / total }\end{array}$ \\
\hline Control & $0 / 8$ & $0 / 116$ \\
GD0 & $0 / 9$ & $0 / 93$ \\
GD1 & $0 / 8$ & $0 / 100$ \\
GD2 & $0 / 7$ & $0 / 95$ \\
GD3 & $0 / 7$ & $0 / 74$ \\
GD4 & $1 / 8$ & $1 \mathrm{a} / 74$ \\
GD5 & $0 / 9$ & $0 / 76$ \\
GD6 & $3 / 9$ & 4 b/98 \\
\hline
\end{tabular}

a: The fetus represented exencephaly.

b: Each fetus represented agnathia, micrognathia, omphalocele or kinked tail.

Table 4. Frequency of visceral malformations and variations in live fetuses.

\begin{tabular}{lcccc}
\hline Group & $\begin{array}{c}\text { No. of litters with } \\
\text { malformation / total }\end{array}$ & $\begin{array}{c}\text { No. of fetuses with } \\
\text { malformation / total }\end{array}$ & $\begin{array}{c}\text { No. of litters with } \\
\text { variations b/total }\end{array}$ & $\begin{array}{c}\text { No. of fetuses with } \\
\text { variations b/total }\end{array}$ \\
\hline Control & $0 / 6$ & $0 / 90$ & $5 / 6$ & $8 / 90$ \\
GD0 & $0 / 7$ & $0 / 63$ & $2 / 7$ & $3 / 63$ \\
GD1 & $0 / 5$ & $0 / 54$ & $2 / 5$ & $4 / 54$ \\
GD2 & $0 / 5$ & $0 / 46$ & $2 / 5$ & $2 / 46$ \\
GD3 & $1 / 4$ & 1 a $/ 41$ & $4 / 4$ & $5 / 41$ \\
GD4 & $0 / 5$ & $0 / 50$ & $4 / 5$ & $7 / 50$ \\
GD5 & $0 / 5$ & $0 / 23$ & $0 / 5$ & $0 / 23^{*}$ \\
GD6 & $0 / 5$ & $0 / 54$ & $1 / 5$ & $1 / 54^{*}$ \\
\hline
\end{tabular}

a: The fetus represented ventricular septum defect.

b: Variations consisted of thymic remnant in the neck, persistent left umbilical artery, variation of lobation of lung, dilated ureter, and dilated renal pelvis. 
cell stage with $1 \mathrm{mM}$ MMS for $1 \mathrm{hr}$ in vitro followed by their transplantation into the oviduct of female mice resulted in embryonic death and growth retardation but not in an increase in the frequency of gross abnormalities in term fetuses (Fabro et al., 1984).

In rats, the hatching blastocyst begins to adhere to the implantation chamber on the morning of gestation day 5.5 (Yasuda and Sato, 1980). In contrast, approximately $50 \%$ of blastocysts implant on gestation day 4.5 in the mouse (Rutledge et al., 1994). In the present study, the GD5 and GD6 groups, in which MMS was administered in the peri-implantation period, showed intrauterine growth retardation in term fetuses. In addition, the placental weight was decreased in the GD6 group. It is possible that the polar extraembryonic ectoderm (trophectoderm) was damaged by MMS treatment at the time of implantation and failed to develop into the ectoplacental cone, resulting in failure of nor- mal placental development. The intrauterine growth retardation induced by MMS exposure at the periimplantation stage may thus result from placental hypoplasia.

It is known that dynamic epigenetic modification of the genome occurs during early development, i.e., active demethylation of the paternal genome occurs in the zygote, followed by passive demethylation during cleavage stages up to the morula stage, and de novo DNA methylation occurs in the inner cell mass of the blastocyst (Santos et al., 2002; Santos and Dean, 2004). Active demethylation of the male pronucleus in rat zygotes proceeds with a slower kinetic than that in mouse embryo, and the rat zygotes at $16 \mathrm{hr}$ after copulation still exhibited detectable methylation on the male pronucleus (Zaitseva et al., 2007). Fertilization of oocytes by spermatozoa with DNA damage induced by exposure to cyclophosphamide, an alkylating agent,

Table 5. Frequency of skeletal malformations and variations in live fetuses.

\begin{tabular}{lcccc}
\hline Group & $\begin{array}{c}\text { No. of litters with } \\
\text { malformation / total }\end{array}$ & $\begin{array}{c}\text { No. of fetuses with } \\
\text { malformation / total }\end{array}$ & $\begin{array}{c}\text { No. of litters with } \\
\text { variations c/total }\end{array}$ & $\begin{array}{c}\text { No. of fetuses with } \\
\text { variations c/total }\end{array}$ \\
\hline Control & $0 / 6$ & $0 / 90$ & $4 / 6$ & $5 / 90$ \\
GD0 & $0 / 7$ & $0 / 62$ & $4 / 7$ & $15 / 62$ \\
GD1 & $1 / 5$ & $1 \mathrm{a} / 53$ & $2 / 5$ & $4 / 53$ \\
GD2 & $1 / 5$ & 1 b/44 & $3 / 5$ & $7 / 44$ \\
GD3 & $0 / 4$ & $0 / 40$ & $3 / 4$ & $4 / 40$ \\
GD4 & $0 / 5$ & $0 / 50$ & $4 / 5$ & $9 / 50$ \\
GD5 & $0 / 5$ & $0 / 20$ & $1 / 5$ & $3 / 20$ \\
GD6 & $0 / 5$ & $0 / 53$ & $3 / 5$ & $4 / 53$
\end{tabular}

a: The fetus represented misshapen thoracic centrum and fused ribs.

b: The fetus represented misshapen thoracic centrum.

c: Variations consisted of bipartite ossification of thoracic centrum, dumbbell ossification of thoracic centrum, short supernumerary rib, full supernumerary rib, fused sternebra, bipartite ossification of sternebra, and misshapen sternebra.

Table 6. Progress of ossifications in live fetuses.

\begin{tabular}{|c|c|c|c|c|c|c|}
\hline \multirow[b]{2}{*}{ Group } & \multirow{2}{*}{$\begin{array}{l}\text { No. of litters with } \\
\text { delayed ossification a } \\
\text { /total }\end{array}$} & \multirow{2}{*}{$\begin{array}{l}\text { No. of fetuses with } \\
\text { delayed ossification a } \\
\text { /total }\end{array}$} & \multicolumn{4}{|c|}{ No. of ossified bones ${ }^{b}$} \\
\hline & & & Sternebrae & Metacarpal & Metatarsal & $\begin{array}{c}\text { Sacral/caudal } \\
\text { vertebrae }\end{array}$ \\
\hline Control & $1 / 6$ & $1 / 90$ & $5.6 \pm 0.6$ & $3.6 \pm 0.4$ & $4.0 \pm 0.0$ & $8.4 \pm 0.6$ \\
\hline GD0 & $2 / 7$ & $3 / 62$ & $4.7 \pm 1.0$ & $3.5 \pm 0.5$ & $3.9 \pm 0.2$ & $7.2 \pm 1.3$ \\
\hline GD1 & $0 / 5$ & $0 / 53$ & $5.7 \pm 0.2$ & $3.8 \pm 0.3$ & $4.0 \pm 0.0$ & $8.6 \pm 0.9$ \\
\hline GD2 & $1 / 5$ & $1 / 44$ & $5.7 \pm 0.3$ & $3.7 \pm 0.2$ & $4.0 \pm 0.0$ & $8.6 \pm 1.0$ \\
\hline GD3 & $1 / 4$ & $1 / 40$ & $5.2 \pm 0.9$ & $3.6 \pm 0.5$ & $4.0 \pm 0.1$ & $7.8 \pm 0.9$ \\
\hline GD4 & $2 / 5$ & $3 / 50$ & $4.6 \pm 1.4$ & $3.6 \pm 0.4$ & $3.9 \pm 0.1$ & $8.2 \pm 0.7$ \\
\hline GD5 & $0 / 5$ & $0 / 20$ & $5.0 \pm 0.9$ & $3.1 \pm 0.2$ & $3.8 \pm 0.4$ & $7.4 \pm 0.8^{*}$ \\
\hline GD6 & $2 / 5$ & $3 / 53$ & $4.9 \pm 0.9$ & $3.5 \pm 0.2$ & $4.0 \pm 0.0$ & $8.0 \pm 0.4$ \\
\hline
\end{tabular}

a: Delay of ossification in the interparietal, occipital, cervical arches or pubis.

b: Data are means \pm S.D. ${ }^{*} \mathrm{p}<0.05$ versus control. 
Susceptibility of rat embryos to methyl methanesulfonate.

resulted in aberrant epigenetic reprogramming in the preimplantation rat embryo (Barton et al., 2005). Methylation of genomic DNA is an epigenetic mark that is modified during the preimplantation period and plays an essential role in the regulation of chromatin structure and gene expression during normal development of mammalian embryos (Bird, 2002; Li, 2002; Santos and Dean, 2004). Aberrant DNA methylation in early embryos results in developmental failure (Li et al., 1993; Li, 2002; Shi and Haaf, 2002). Abnormal epigenetic reprogramming has also been shown to affect embryonic development in cloned animals (Dean et al., 2001; Santos et al., 2003), and placental hypertrophy in cloned animals is associated with aberrant hypermethylation in the placental genome (Ohgane et al., 2004). MMS methylates DNA at the N7 position of guanine and the N3 position of adenine (Pegg, 1984). Exposure of rat zygotes or embryos at the peri-implantation stage to MMS in the present study may thus have resulted in aberrant epigenetic reprogramming of the embryo as well as aberrant methylation in the placenta responsible for the observed placental hypertrophy or hypoplasia. Placental hypertrophy is also associated with maternal anemia as a compensatory response (Agboola and Roluga, 1978; Kuizon et al., 1985; Wheeler et al., 1995; Huang et al., 2001). However, we did not detect any effect of MMS on erythrocyte parameters, including hemoglobin level, of the dams in the present study.

In conclusion, we have shown that effects of exposure of rat dams to MMS during the pregastrulation period on embryonic development depend on the precise time of exposure. It remains to be determined whether these effects reflect direct or indirect actions of MMS in the embryo, placenta, or maternal systems.

\section{ACKNOWLEDGMENT}

We thank Y. Maruyama, T. Chino, Y. Terashima, K. Yasue, and T. Tahara of the Toxicology Research Laboratories, Kissei Pharmaceutical Co. Ltd., for their assistance with the experiments and management of the rats.

\section{REFERENCES}

Agboola, A. and Roluga, I.A. (1978): The water and nitrogen composition of the placenta in anemic women. Int. J. Gynaecol. Obstet., 15, 462-463.

Aliverti, V., Bonanomi, L., Giavini, E., Leone, V.G., Mariani, L., Prati, M. and Vismara, C. (1982):
Embryotoxic effects of 5-hydroxytryptamine during the peri-implantation period in the rat. Biol. Reprod., 27, 1231-1237.

Ashby, J., Lefevre, P.A., Elliott, B.M. and Clapp, M.L. (1996): Methyl methanesulphonate (MMS) as a resource conserving and reliable positive control agent for male rat and male mouse dominant lethal assays. Mutagenesis, 11, 611-613.

Barton, T., Robaire, B. and Hales, B.F. (2005): Epigenetic programming in the preimplantation rat embryo is disrupted by chronic paternal cyclophosphamide exposure. Proc. Natl. Acad. Sci. USA, 102, 7865-7870.

Bird, A. (2002): DNA methylation patterns and epigenetic memory. Genes. Dev., 16, 6-21.

Brewen, J.G., Payne, H.S., Jones, K.P. and Preston, R.J. (1975): Studies on chemically induced dominant lethality. I. The cytogenetic basis of MMS-induced dominant lethality in post-meiotic male germ cells. Mutat. Res., 33, 239-250.

Dean, W., Santos, F., Stojkovic, M., Zakhartchenko, V., Walter, J., Wolf, E. and Reik, W. (2001): Conservation of methylation reprogramming in mammalian development: Aberrant reprogramming in cloned embryos. Proc. Natl. Acad. Sci. USA, 98, 13734-13738.

Ehling, U.H. and Neuhauser-Klaus, A. (1990): Induction of specific-locus and dominant lethal mutations in male mice in the low dose range by methyl methanesulphonate (MMS). Mutat. Res., 230, 61-70.

Fabro, S., McLachlan, J.A. and Dames, N.M. (1984): Chemical exposure of embryos during the preimplantation stages of pregnancy: Mortality rate and intrauterine development. Am. J. Obstet. Gynecol., 148, 929-938.

Fisher, R.A. (1922): On the interpretation of chisquare from contingency tables and the calculation ofP. J. Royal Stat Sci., 85, 87-94.

Generoso, W., Rutledge, J.C., Cain, K.T., Hughes, L.A. and Braden, P.W. (1987): Exposure of female mice to ethylene oxide within hours after mating leads to fetal malformation and death. Mutat. Res., 176, 269-274.

Generoso, W., Rutledge, J.C., Cain, K.T., Hughes, L.A. and Downing, D.J. (1988): Mutageninduced fetal anomalies and death following treatment of females within hours after mating. Mutat. Res., 199, 175-181.

Generoso, W., Shourbaji, A.G., Piegorsch, W.W. and Bishop, J.B. (1991): Developmental response of 
zygotes exposed to similar mutagens. Mutat. Res., 250, 439-446.

Graeter, L.J., Wolfe, R.E., Kinkead, E.R. and Flemming, C.D. (1998): Effects of ammonium dinitramide on preimplantation embryos in Sprague-Dawley rats. Toxicol. Ind. Health, 14, 789-798.

Huang, A., Zhang, R. and Yang, Z. (2001): Quantitative (stereological) study of placental structures in women with pregnancy iron-deficiency anemia. Eur. J. Obstet. Gynecol. Reprod. Biol., 97, 59-64.

Iannaccone, P., Bossert, N.L. and Connelly, C.S. (1987): Disruption of embryonic and fetal development due to preimplantation chemical insults: A critical review. Am. J. Obstet. Gynecol., 157, 476-484.

Ichihara, K. (1996): Mann-Whitney test (non-parametric test). In Statistics for Bioscience $\left(10^{\text {th }} \mathrm{ed}.\right)$, pp. 90-99, Nankodo, Tokyo.

Jacquet, P., de Saint-Georges, L., Vankerkom, J. and Bangnet-Mahieu, L. (1995): Embryonic death, dwarfism and fetal malformations after irradiation of embryos at the zygote stage: Studies on two mouse strains. Mutat. Res., 332, 73-87.

Jensh, R.P. and Brent, R.L. (1966): Rapid schedules for $\mathrm{KOH}$ clearing and alizarin red $\mathrm{S}$ staining of fetal rat bone. Stain Technol., 41, 179-183.

Katoh, M. and Tanaka, N. (1980): Relationship between chromosome aberrations in the firstcleavage metaphases and unscheduled DNA synthesis following paternal MMS treatment. Jpn. J. Genet., 55, 55-65.

Kuizon, M., Cheong, R.L., Ancheta, L.P., Desnacido, J.A., Macapinlac, M.P. and Baens, J.S. (1985): Effect of anaemia and other maternal characteristics on birthweght. Hum. Nutr. Clin. Nutr., 39, 419-426.

Li, E. (2002): Chromatin modification and epigenetic reprogramming in mammalian development. Nat. Rev. Genet., 3, 662-673.

Li, E., Beard, C. and Jaenisch, R. (1993): Role for DNA methylation in genomic imprinting. Nature, 366, 362-365.

Nagao, T. (1994): Developmental abnormalities due to exposure of mouse paternal germ cells, preimplantation embryos, and organogenic embryos to acrylamide. Cong. Anom., 34, 35-46.

Nagao, T. (1996): Exposure to ethylnitrosourea before implantation induces malformations in mouse fetuses. Cong. Anom., 36, 83-94.
Nagao, T., Ishizuka, Y. and Mizutani, M. (1986): Effects of mitomycin $\mathrm{C}$ treatment before implantation on development of mouse embryo. Cong. Anom., 26, 93-101.

Nagao, T., Morita, Y., Ishizuka, Y., Wada, A. and Mizutani, M. (1991): Induction of fetal malformations after treatment of mouse embryos with methylnitrosourea at the preimplantation stages. Teratog. Carcinog. Mutagen., 11, 1-10.

Nagao, T., Saitoh, Y. and Yoshimura, S. (2000): Possible mechanism of congenital malformations induced by exposure of mouse preimplantation embryos to mitomycin C. Teratology, 61, 248261.

Nagao, T., Shirota, M. and Sato, M. (1997): Treatment of mouse preimplantation embryos with adriamycin, methlmethanesulfonate and retinoic acid results in congenital defects. Cong. Anom., 37, 21-29.

Nishimura, K. (1974): Microdissection method for detecting thoracic visceral malformations in mouse and rat fetuses. Cong. Anom., 14, 23-40.

Ohgane, J., Wakayama, T., Senda, S., Yamazaki, Y., Inoue, K., Ogura, A., Marh, J., Tanaka, S., Yamagimachi, R. and Shiota, K. (2004): The Sall3 locus is an epigenetic hotspot of aberrant DNA methylation associated with placentomegaly of cloned mice. Genes. Cells, 9, 253-60.

Pegg, A. (1984): Methylation of the O6 position of guanine in DNA is the most likely initiating event in carcinogenesis by methylating agents. Cancer. Invest., 2, 223-231.

Russell, L.B. (1950): X-ray induced developmental abnormalities in the mouse and their use in the analysis of embryological patterns. I. J. Exp. Zool., 114, 545-601.

Russell, L.B. (1954): The effects of radiation on mammalian prenatal development. In Radiation biology (Hollaender, A., eds.), vol. 1, pp. 861-918, McGraw-Hill, New York.

Russell, L.B. and Russell, W.L. (1950): The effects of radiation on the preimplantation stages of the mouse embryo. Anat. Rec., 108, 521.

Russell, L.B. and Russell, W.L. (1952): Radiation hazards to the embryo and fetus. Radiology, 58, 369-376.

Rutledge, J. (1997): Developmental toxicity induced during early stages of mammalian embryogenesis. Mutat. Res., 396, 113-127.

Rutledge, J., Generoso, W.M., Shourbaji, A., Cain, K.T., Gans, M. and Oliva, J. (1992): Develop- 
Susceptibility of rat embryos to methyl methanesulfonate.

mental anomalies derived from exposure of zygotes and first-cleavage embryos to mutagens. Mutat. Res., 296, 167-177.

Rutledge, J.C., Shourbaji, A.G., Hughes, L.A., Polifka, J.E., Cruz, Y.P., Bishop, J.B. and Generoso, W.M. (1994): Limb and lower-body duplications induced by retinoic acid in mice. Proc. Natl. Acad. Sci. USA, 91, 5436-5440.

Santos, F. and Dean, W. (2004): Epigenetic reprogramming during early development in mammals. Reproduction, 127, 643-651.

Santos, F., Hendrich, B., Reik, W. and Dean, W. (2002): Dynamic reprogramming of DNA methylation in the early mouse embryo. Dev. Biol., 241, 172-182.

Santos, F., Zakhartchenko, V., Stojkovic, M., Peters, A., Jenuwein, T., Wolf, E. and Reik, W. (2003): Epigenetic marking correlates with developmental potential in cloned bovine preimplantation embryos. Curr. Biol., 12, 1116-1121.

Shi, W. and Haaf, T. (2002): Aberrant methylation patterns at the two-cell stage as an indicator of early developmental failure. Mol. Reprod. Dev., 63, 329-334.

Tanaka, N. (1981): Studies on chemical induction of chromosomal aberrations in postcopulation germ cells and zygotes of female mice. I. Comparative studies on the frequency of first-cleavage chromosomal aberrations and dominant lethal mutations. Jpn. J. Genet., 56, 117-129.

Wheeler, T., Elcock, C.L. and Anthony, F.W. (1995): Angiogenesis and the placental environment. Placenta, 16, 289-296.

Witschi, E. (1962): Development: Rat. In Growth Including Reproduction and Morphological Development, (Altman, P.L. and Dittmer, D.S., eds.), pp.304-314, Biological Handbooks of the Federation of American Societies for Experimental Biology, Washington.

Yasuda, Y. and Sato, S. (1980): A morphological study on the early fertilized ova in rat-with special reference to the temporal changes of zona pellucida and implantation process of blastocyst. Jikken Dobutsu., 29, 15-26.

Zaitseva, I., Zaitsev, S., Alenina, N., Bader, M. and Krivokharchenko, A. (2007): Dynamics of DNA-demethylation in early mouse and rat embryos developed in vivo and in vitro. Mol. Reprod. Dev., 74, 1255-1261. 